\title{
A study on presentation and management of ectopic pregnancy at tertiary care hospital
}

\author{
Tarini Singh ${ }^{1}$, Sanil Mohan ${ }^{2}$, Shikha Aggarwal ${ }^{3}$, Debkalyan Maji ${ }^{2 *}$
}

\begin{abstract}
${ }^{1}$ Department of Obstetrics and Gynaecology, GMC and SMGS Hospital, Jammu, Jammu and Kashmir, India
${ }^{2}$ Department of Obstetrics and Gynaecology, Military Hospital, Gwalior, India

${ }^{3}$ Department of Obstetrics and Gynaecology, Altnagelvin Hospital, Northern Ireland, UK
\end{abstract}

Received: 12 March 2021

Accepted: 12 April 2021

\author{
*Correspondence: \\ Dr. Debkalyan Maji, \\ E-mail: dr.debkalyan@gmail.com
}

Copyright: (c) the author(s), publisher and licensee Medip Academy. This is an open-access article distributed under the terms of the Creative Commons Attribution Non-Commercial License, which permits unrestricted non-commercial use, distribution, and reproduction in any medium, provided the original work is properly cited.

\begin{abstract}
Background: Ectopic pregnancy and its consequences are the most severe form of obstetric emergency during first trimester of pregnancy. It is a kind of life threatening emergency leading to significant maternal morbidity and even mortality.

Methods: A prospective study was conducted at a tertiary care teaching hospital of Northern India from 01 Jan 2020 to 31 Mar 2020. All cases of ectopic pregnancy which were admitted and managed during this study period were included in the study. All collected data were analysed with Epitable 6.04 version and SPSS version 20 software.

Results: During the study period total 32 cases of ectopic pregnancy were studied. Classical symptoms of amenorrhoea, pain abdomen and bleeding per vaginum were observed in $62.50 \%$ cases whereas $93.75 \%$ cases were associated with pain abdomen only and $71.88 \%$ cases had the symptoms of bleeding per vaginum only. All cases were managed surgically. The incidence of ectopic pregnancy was one in 200 delivered pregnancy. Most case were multiparas and common in $27-32 \mathrm{yr}$ age group (53.13\%). Tubal ectopic pregnancy was common in right side (63\%). Approximately $81 \%$ cases presented with haemoperitoneum and $63 \%$ cases required blood transfusion.

Conclusions: Ectopic pregnancy mostly presents as an obstetrics emergency in our hospital especially with rupture ectopic pregnancy with haemoperitoneum. Early diagnosis and intervention suited best for the situation is mainstay for favourable and successful outcome.
\end{abstract}

Keywords: Blood transfusion, Ectopic pregnancy, Haemoperitoneum, Obstetric emergency, Salpingectomy

\section{INTRODUCTION}

Ectopic pregnancy is one of the commonest cause of obstetrics emergency as well as maternal morbidity and mortality during first trimester of pregnancy. Management of ectopic pregnancy has changed and improved over time. In 1903 J. Whitridge Williams said following words regarding management of ectopic pregnancy - "As soon as an unruptured extra-uterine pregnancy is positively diagnosed, its immediate removal by laparotomy is urgently indicate, since rupture may occur at any time and the patient die from haemorrhage before operative aid can be obtained. ${ }^{1}$
But in present scenario, we have multiple options like medical, surgical route via laparotomy or laparoscopy in our armamentarium to manage ectopic pregnancy. Still ectopic pregnancy remains the leading cause of early pregnancy related death. ${ }^{1}$ Ectopic pregnancy and its consequences contributes approx $19 \%$ of maternal near miss with case fatality index of $2.85 \% .^{2}$ It is responsible for $4.34 \%$ of maternal mortality even in today's scenario as reported by $\mathrm{S}$ Chaudhury in their study based on tertiary case teaching hospital in Kolkata. ${ }^{2}$ In this background, we have conducted the present study to evaluate the presentation and outcome of management of ectopic pregnancy in our tertiary care teaching hospital. 


\section{METHODS}

A prospective observational study was conducted at our tertiary care Government Medical College and hospital at Jammu, Jammu and Kashmir, India. The Study duration was from 01 Jan 2020 to 01 Mar 2020. The institutional ethical approval was taken prior to conduct of study. Informed consents were taken from all patients who participated in the study.

The study population comprised of patients with ectopic pregnancy who had reported to Accident and Emergency Department (A and E Dept.) or Obstetrics and Gynaecology Out Patient Department (GOPD) and thereafter admitted and managed. During the study period total number of 32 cases were admitted with diagnosis of ectopic pregnancy.

\section{Inclusion and exclusion criteria}

All patient with ectopic pregnancy who underwent admission and management during the study period were included in the study. Patients who refused hospital admission in view of medical management were excluded.

\section{Parameter and statistical analysis}

Demographic profile of patients, clinical sign and symptoms, obstetrics parameters like gravida, parity, period of gestation (POG), site and side of ectopic pregnancy, hospital stay and blood transfusion status were recorded. All statistical analysis pertaining to study was carried out by Neo-Epitable version 6.04 software and SPSS version 20 software.

\section{RESULTS}

During the study period total 32 patients were attended and admitted with ectopic pregnancy. One patient was presented to A and E Dept with history of bleeding per vaginum, pain abdomen, drowsiness, unresponsiveness and hypotensive shock. She was immediately resuscitated and taken for emergency laparotomy and haemostasis. The patient was diagnosed with ruptured ectopic pregnancy with haemoperitoneum. However, she developed sudden cardiorespiratory arrest intraop, CPR was initiated and revived. Subsequently she died during post-operative period in spite of putting best possible efforts to save her with multidisciplinary team approach.

There were total 6293 patients delivered in our institution during the study period. This made the incidence of ectopic pregnancy of $0.508 \%$ i.e aprox 5 per 1000 deliveries. The mean age group of study population was $28.28 \pm 4.19$ (1 SD) yrs with 95\% CI (confidence Interval) 26.78 to 29.78 yrs and range of patients age were 20 to 38 years (Median age $28 \mathrm{yrs}$ ).
The age group of patients from 27 to $32 \mathrm{yr}$ was maximum (53.13\%). The other two age group i.e $20-2626 \mathrm{yrs}$ and $33-38$ yrs were $34.38 \%$ and $12.50 \%$ respectively. Majority of study population belonged to Hindu $(53.13 \%)$. The proportion of religion i.e Muslims and Sikhs were $28.13 \%$ and $18.75 \%$ respectively (Table 1 ).

Table 1: Distribution of patient according to demography and clinical history.

\begin{tabular}{|c|c|c|c|}
\hline \multicolumn{2}{|c|}{ Characteristics } & $\begin{array}{l}\text { Frequency } \\
\text { (n) }\end{array}$ & $\begin{array}{l}\text { Percentage } \\
(\%)\end{array}$ \\
\hline \multirow{3}{*}{ Religion } & Hindu & 17 & 53.12 \\
\hline & Muslim & 9 & 28.13 \\
\hline & Sikh & 6 & 18.75 \\
\hline \multirow{3}{*}{$\begin{array}{l}\text { Age group } \\
\text { in yrs }\end{array}$} & 20 to 26 & 11 & 34.38 \\
\hline & 27 to 32 & 17 & 53.13 \\
\hline & 33 to 38 & 4 & 12.50 \\
\hline \multirow{4}{*}{ Gravida } & 1 & 4 & 12.50 \\
\hline & 2 & 5 & 15.62 \\
\hline & 3 & 13 & 40.63 \\
\hline & 4 & 10 & 31.25 \\
\hline \multirow{4}{*}{ Parity } & 0 & 6 & 18.75 \\
\hline & 1 & 10 & 31.25 \\
\hline & 2 & 10 & 31.25 \\
\hline & 3 & 6 & 18.75 \\
\hline \multirow{4}{*}{ Abortion } & 0 & 21 & 65.62 \\
\hline & 1 & 8 & 25.00 \\
\hline & 2 & 2 & 6.25 \\
\hline & 3 & 1 & 3.13 \\
\hline \multirow{2}{*}{$\begin{array}{l}\text { History of } \\
\text { ectopic } \\
\text { pregnancy }\end{array}$} & 0 & 31 & 96.88 \\
\hline & 1 & 1 & 3.12 \\
\hline
\end{tabular}

In the study population, it was found that ectopic pregnancy was highest in third gravida (40.63\%) and same among second and third para $(31.25 \%)$. Ectopic pregnancy was found more among the patients with history of no abortion - comprised $65.63 \%$ of patients. $96.88 \%$ of patient $(31 / 32)$ with no history of ectopic pregnancy were admitted and treated (Table 1).

Overall $62.50 \%$ of ectopic pregnancies were found on right side (20/32). Total ruptured cases of ectopic pregnancy were $81.25 \%$ (26/32). Left sided ruptured ectopic cases were more common $(83.33 \%)$ and right side ruptured case were $80.00 \%$ ( $\mathrm{p}$ value 0.815). Most common site of rupture of ectopic pregnancy was ampulla of fallopian tube i.e 78.13\% (25/31) (Table 2).

Classical triad of ectopic pregnancy i.e amenorrhoea, pain lower abdomen and bleeding per vaginum was only present in $62.50 \%$ of cases. In our study group we found pain lower abdomen was the most common presenting symptom. Urinary BHCG test was negative in $9.38 \%$ $(3 / 32)$ of cases. 
After admission all cases underwent emergency laparotomy and $93.75 \%$ (30/32) cases were done under regional spinal anaesthesia. 20 out of 32 cases $(62.50 \%)$ were administered blood and blood products (Packed $\mathrm{RBC} / \mathrm{FFP}$ ) in per operative/post operative period (Table 2).

Table 2: Distribution of different clinical parameter of study population.

\begin{tabular}{|c|c|c|c|c|c|}
\hline \multirow{2}{*}{ Characteristics } & & \multirow{2}{*}{ Frequency (n) } & \multirow{2}{*}{ Percentage (\%) } & \multicolumn{2}{|c|}{ 95\% Confidence Interval } \\
\hline & & & & Lower & Upper \\
\hline \multirow{2}{*}{ Side } & Left & 12 & 37.50 & 21.66 & 56.25 \\
\hline & Right & 20 & 62.50 & 43.74 & 78.33 \\
\hline \multirow{4}{*}{$\begin{array}{l}\text { Site of ectopic } \\
\text { pregnancy }\end{array}$} & Ampulla & 25 & 78.13 & 59.56 & 90.06 \\
\hline & Isthmus & 2 & 6.25 & 1.09 & 22.22 \\
\hline & Fimbrial & 4 & 12.50 & 4.08 & 29.93 \\
\hline & Interstitial & 1 & 3.13 & 0.16 & 17.99 \\
\hline \multirow{2}{*}{ Ruptured } & Yes & 26 & 81.25 & 62.96 & 92.14 \\
\hline & No & 6 & 18.75 & 7.86 & 37.05 \\
\hline \multirow{2}{*}{ Anaesthesia } & Spinal & 30 & 93.75 & 77.78 & 98.91 \\
\hline & GA & 2 & 6.25 & 1.09 & 22.22 \\
\hline \multirow[t]{2}{*}{ Blood transfusion } & Yes & 20 & 62.50 & 43.75 & 78.34 \\
\hline & No & 12 & 37.50 & 21.66 & 56.25 \\
\hline \multirow{2}{*}{ UPT } & Yes & 29 & 90.63 & 73.83 & 97.55 \\
\hline & No & 3 & 9.38 & 2.45 & 26.17 \\
\hline \multirow{2}{*}{ Bleeding per vaginum } & Yes & 23 & 71.88 & 53.02 & 85.60 \\
\hline & No & 9 & 28.13 & 14.40 & 46.98 \\
\hline \multirow{2}{*}{ Pain abdomen } & Yes & 30 & 93.75 & 77.78 & 98.91 \\
\hline & No & 2 & 6.25 & 1.09 & 22.22 \\
\hline \multirow{2}{*}{$\begin{array}{l}\text { Classical Triad } \\
(\text { Amenorrhoea + pain } \\
\text { Abdo + Bleeding PV) }\end{array}$} & Yes & 20 & 62.50 & 43.75 & 78.34 \\
\hline & No & 12 & 37.50 & 21.66 & 56.25 \\
\hline
\end{tabular}

The box and whisker plot showed that there was one outlier value of $\mathrm{Hb}$ level, mean and median value of $\mathrm{Hb}$ $\%$ of the study population were $9.67 \pm 1.85 \mathrm{gm} / \mathrm{dl}$ ( Mean $\pm \mathrm{I} \mathrm{SD}$ ) and $10.01 \mathrm{gm} / \mathrm{dl}$ respectively (Figure 1).

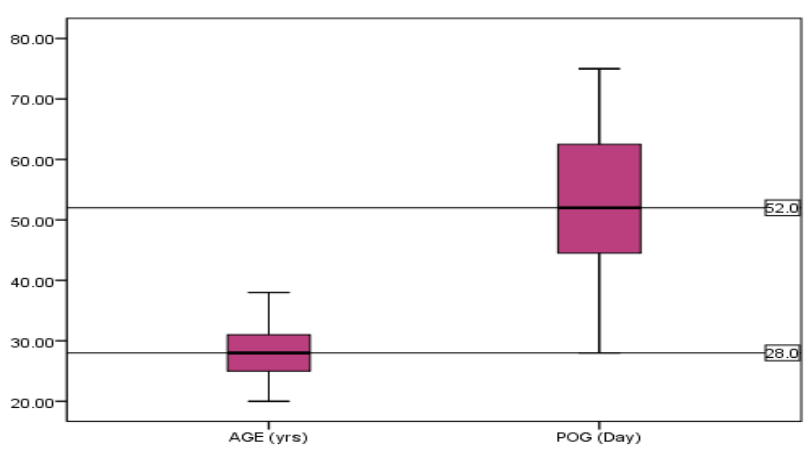

Figure 1: Age and period of gestation distribution.

The mean period of gestation of detection of ectopic pregnancy was $52.81 \pm 11.43$ days. The length of hospital admission was ranged from one to five days. Most patient were discharged on 3th post op day (Mean - 3.31 days, Mode -3 days) and it comprised of $71.88 \%$ (23/32) of study population (Figure 2).

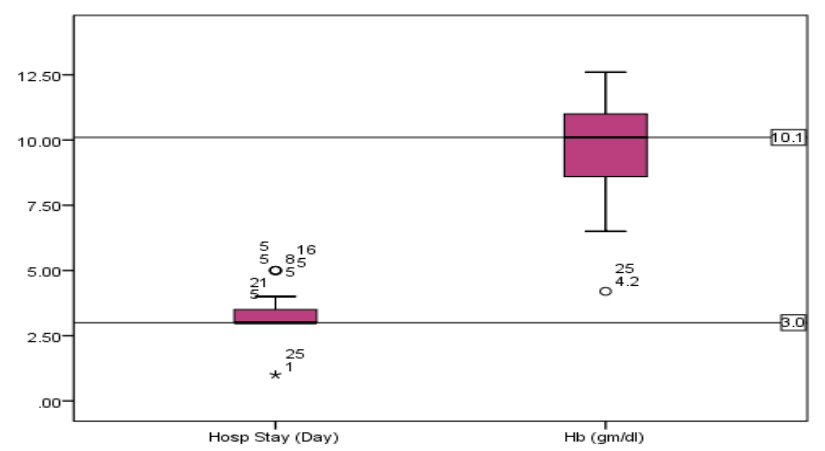

Figure 2: Hb level and hospital stay distribution.

\section{DISCUSSION}

During literature search we came to know that the first diagnosis of ectopic pregnancy as cause of maternal mortality was known to us in eleventh century. In 1759 the report of first successful surgical management of ectopic pregnancy was made by Surgeon Dr John Bard, New York USA. Salpingectomy as surgical intervention for ruptured ectopic was first done by Scottish surgeon Dr Robert Lawson Tait in $1883 .^{3}$ Thereafter salpingectomy became a standard practice for management of ruptured ectopic pregnancy. 
The incidence of ectopic pregnancy has increased since last few decades due to increased adoption of medically assisted reproductive (MAR) technique. However, the morbidity and mortality are decreasing due to advancement of medical technique, early detection and increased awareness of clientele. A study conducted by Samiya Mufti et al at LD Hospital Srinagar J\&K reported the incidence of ectopic pregnancy was 3.99 per 1000 deliveries. ${ }^{4}$ Royal College of Obstetrics and Gynaecolgist (RCOG) in their guideline reported the incidence of ectopic pregnancy in UK was 11 per 1000 deliveries. ${ }^{5}$ In our study we found the incidence of ectopic pregnancy was 5 per 1000 deliveries.

The commonest predisposing factors for ectopic pregnancy were tubectomy, pelvic inflammatory disease, history of abortion / ectopic pregnancy. ${ }^{6}$ Parous ladies are more prone to have ectopic pregnancy than nullipara lady. Our study is also consistence with the finding of the study reported by Prasanna B et al. ${ }^{7}$ The probable cause of this increase rate of ectopic pregnancy is attributable to more association of predisposing factor of ectopic pregnancy with non-nulliparous group.

Several studies suggested tubal ectopic pregnancy has been affected right side more than left side. ${ }^{6,8}$ Our study also found the frequency of ectopic pregnancy on right side was more than that of left side. The study also yields statistically insignificant increased number of cases on the left fallopian tube with $\mathrm{p}$ value of 0.815 .

The classical presentation of ectopic pregnancy is characterized by triad of delayed menstruation/ amenorrhoea, pain and vaginal bleeding or spotting. ${ }^{1}$ Present study has revealed only $62.50 \%$ cases presented with classical triad. Pain abdomenwere the most common presentation and our findings were consistent with the published studies of Gupta R et. Al. ${ }^{9}$ All cases in our study was admitted through $\mathrm{A}$ and $\mathrm{E}$ department and more than two third cases (approx. 78\%) presented with clinical features of shock. Approx. 62\% cases required blood transfusion in our set up. These finding were consistent with other studies from India. ${ }^{10}$

\section{CONCLUSION}

Ectopic pregnancy is still one of the major contributor of early pregnancy emergency admission, morbidity and mortality. Majority cases present with pain abdomen and amenorrhea. Clinical signs of shock are present in most of cases too. High degree of clinical suspicion and early intervention are main stay for successful outcome.
Funding: No funding sources

Conflict of interest: None declared

Ethical approval: The study was approved by the Institutional Ethics Committee

\section{REFERENCES}

1. Cunningham F, Gray LKJ, Bloom SL, Jodi D, Hoffman S, Barbara L, et al. Ectopic Pregnancy. In: Cunningham F Gray LKJ, Bloom S L, Dashe Jodi S, Hoffman Barbara L, Casey Brian M,Spong Catherine Y, editor. Williams Obstetrics. $25^{\text {th }}$ ed: McGraw-Hill Education; 2018;371-87.

2. Chaudhuri S, Nath S. Life-threatening Complications in Pregnancy in a Teaching Hospital in Kolkata, India. J Obstetrics and Gynecol India. 2019;69(2):115-22.

3. Chaudhary P, Manchanda R, Patil VN. Retrospective study on laparoscopic management of ectopic pregnancy. $\mathbf{J}$ Obstetrics and Gynaecol India. 2013;63(3):173-6.

4. Mufti S, Rathe S, Mufti S, Rangrez RA, Khalida W. Ectopic pregnancy: an analysis of 114 cases. JKPractitioner. 2012;17(4):20-3.

5. Diagnosis and Management of Ectopic Pregnancy: Green-top Guideline No. 21. BJOG : an international J Obstetrics and Gynaecol. 2016;123(13):e15-e55.

6. Sudha VS, Delphine RT. A retrospective study on ectopic pregnancy: a two year study. Int J Reprod Contracept Obstet Gynecol. 2016;5:4365-8.

7. Prasanna B, Jhansi CB, Swathi K, Shaik MV. A study on risk factors and clinical presentation of ectopic pregnancy in women attending a tertiary care centre. IAIM, 2016;3(1):90-6.

8. Islam A, Fawad A, Shah AA, Jadoon H, Sarwar I, Abbasi AU. Analysis Of Two Years Cases Of Ectopic Pregnancy. J Ayub Medical College, Abbottabad: JAMC. 2017;29(1):65-7.

9. Shukla DB, Jagtap SV, Kale PP, Thakkar HN. Study of ectopic pregnancy in a tertiary care centre. Int $\mathbf{J}$ Reprod Contracept Obstet Gynecol. 2017;6:975-9.

10. Murugesan A, Prabhu K, Muthulakshmi M. A retrospective study of ectopic pregnancies in a tertiary care hospital. Int J Reprod Contracept Obstet Gynecol. 2016;5:2537-40.

Cite this article as: Singh T, Mohan S, Aggarwal S, Maji D. A study on presentation and management of ectopic pregnancy at tertiary care hospital. Int J Reprod Contracept Obstet Gynecol 2021;10:19972000. 